OPEN ACCESS

Edited by:

Sofie Struyf,

KU Leuven, Belgium

Reviewed by:

Fatemeh Navid,

National Institute of Arthritis and Musculoskeletal and Skin Diseases (NIAMS), United States Laura Lucarini,

University of Florence, Italy

*Correspondence: Mohamed Al-Shabrawey malshabrawey@augusta.edu

Specialty section: This article was submitted to Inflammation,

a section of the journal

Frontiers in Immunology

Received: 02 June 2020 Accepted: 08 December 2020

Published: 29 January 2021

Citation:

Al-Shabrawey M, Hussein $K$, Wang $F$, Wan M, Elmasry K, Elsherbiny N,

Saleh H, Yu PB, Tawfik $A$ and Ibrahim AS (2021) Bone Morphogenetic Protein-2 Induces

Non-Canonical Inflammatory and Oxidative Pathways in Human Retinal Endothelial Cells.

Front. Immunol. 11:568795. doi: 10.3389/fimmu.2020.568795

\section{Bone Morphogenetic Protein-2 Induces Non-Canonical Inflammatory and Oxidative Pathways in Human Retinal Endothelial Cells}

\author{
Mohamed Al-Shabrawey ${ }^{1,2,3,4 *}$, Khaled Hussein ${ }^{1,5}$, Fang Wang ${ }^{1,6}$, Ming Wan ${ }^{1,6}$, \\ Khaled Elmasry ${ }^{1,4}$, Nehal Elsherbiny ${ }^{1,7}$, Heba Saleh ${ }^{1}$, Paul B. Yu ${ }^{8}$, Amany Tawfik $^{1,2,3}$ \\ and Ahmed S. Ibrahim ${ }^{7,9}$

\begin{abstract}
1 Department of Oral Biology and Diagnostic Sciences, Dental College of Georgia, Augusta University, Augusta, GA, United States, 2 Department of Cellular Biology and Anatomy, Medical College of Georgia, Augusta University, Augusta, GA, United States, United States, ${ }^{4}$ Department of Anatomy, Mansoura Faculty of Medicine, Mansoura University, Mansoura, Egypt, ${ }^{5}$ Department of Medicine and Surgery, Oral and Dental Research Division, National Research Centre, Cairo, Egypt, ${ }^{6}$ Department of Traditional Chinese Medicine, School of Medicine, Jianghan University, Wuhan, China, ${ }^{7}$ Department of Biochemistry, Faculty of Pharmacy, Mansoura University, Mansoura, Egypt, ${ }^{8}$ Division of Cardiovascular Medicine, Department of Medicine, Brigham and Women's Hospital and Harvard Medical School, Boston, MA, United States, ${ }^{9}$ Department of Ophthalmology, Visual, and Anatomical Sciences, Department of Pharmacology, Wayne State University, Detroit, MI, United States
\end{abstract} \\ ${ }^{3}$ Department of Ophthalmology and Culver Vision Discovery Institute, Medical College of Georgia, Augusta University, Augusta, GA,
}

The mechanisms of diabetic retinopathy (DR), are not yet fully understood. We previously demonstrated an upregulation of retinal bone morphogenetic protein-2 (BMP2) in experimental diabetes and in retinas of diabetic human subjects. The purpose of current study was to investigate the role of non-canonical inflammatory pathway in BMP2-induced retinal endothelial cell (REC) barrier dysfunction. For this purpose, we used RT-PCR and western blotting to evaluate the levels of BMP2 signaling components (BMP2, BMP4, BMP receptors), VEGF, phosphorylated p38 MAPK and NFkB, and oxidative stress markers in cultured human retinal endothelial cells (HRECs) subjected to BMP2 $(50 \mathrm{ng} / \mathrm{ml})$ for up to $24 \mathrm{~h}$. Also, effect of high glucose ( $\mathrm{HG}, 30 \mathrm{mM}$ D-glucose) on the expression of BMP2 and its downstream genes was examined in HRECs. H2-DCF is a fluorogenic dye that measures the levels of cellular reactive oxygen species (ROS) was used to measure the pro-oxidative effect of BMP2. Moreover, we evaluated the effect of inhibiting p38 and VEGF signaling on BMP2induced HRECs barrier dysfunction by measuring the trans-endothelial cell electrical resistance (TER) using electric cell-substrate impedance sensing (ECIS). We also tested the effect of HG on the integrity of HRECs barrier in the presence or absence of inhibitors of BMP2 signaling. Our data reveals that BMP2 and high glucose upregulates BMP components of the BMP signaling pathway (SMAD effectors, BMP receptors, and TGF $\beta$ ligand itself) and induces

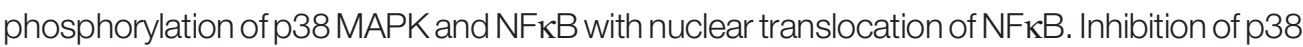
or NFKB attenuated BMP2-induced VEGF expression and barrier dysfunction in HRECs. Also, inhibition of VEGFR2 attenuated BMP2-induced barrier dysfunction. Moreover, BMP2 induces generation of ROS and endothelial nitric oxide synthase (eNOS) expression and activity in HRECs. Finally, HG upregulated BMP2 and its downstream genes (SMAD, BMP4, 
ALKs, and TGF- $\beta$ ) in HRECs and BMP2 inhibitors attenuated HG-induced HRECs barrier dysfunction. Our results suggest that in addition to the regular canonical SMAD signaling BMP2 induces non-canonical inflammatory pathway in HRECs via activation of p38/NFkB pathway that causes the upregulation of VEGF and the disruption of HRECs. Inhibition of BMP2 signaling is a potential therapeutic intervention to preserve endothelial cell barrier function in DR.

Keywords: VEGF - vascular endothelial growth factor, smad, diabetic retinopathy (DR), bone morphogenetic protein - 2, p38 MAKP signaling

\section{INTRODUCTION}

Diabetic retinopathy (DR), a common microvascular complication of diabetes mellitus is considered the most common cause of blindness among working-age people in the world with deleterious socioeconomic impacts (1-3). Loss of blood-retinal barrier (BRB) function is a key stage in the development of DR leading to diabetic macular edema (DME) and subsequently loss of vision $(4,5)$. The cellular components of inner BRB include endothelial cells, pericytes, and glial cells $(6,7)$. Therefore, integrity of retinal endothelial cell barrier is essential to preserve normal function of BRB. Although current therapies including, laser photocoagulation, anti-vascular endothelial growth factor (VEGF), and corticosteroid demonstrated significant efficacy in treating DR and prevention of its progression, they are still limited by their significant side effects incomplete ability to eliminate the risk of blindness, and mostly applied in late stages of the disease (810). Therefore, there is a great demand for the development of novel independent or complementary therapeutic approaches that target primarily the early insults that lead to the development of irreversible visual loss.

Bone morphogenetic proteins (BMPs) are group of cytokines that belong to the transforming growth factors- $\beta$ superfamily and were initially discovered and named for their ability to induce bone and cartilage formation $(11,12)$, however further studies of BMPs signaling pathway resulted in greater understanding of their crucial role. Nowadays they are increasingly recognized as multifunctional regulators of angiogenesis, tissue homeostasis and tumorigenesis, with evidence of activation of BMP signaling activity in different disease contexts (13-16). Among various members of BMPs, BMP2 has been the most studied and clinically relevant member. BMP2 was reported as an osteo-inductive cytokine that induces the entire cascade of cartilage and bone formation. Moreover, many studies linked BMP2 to various organs development including lung, heart, and central nervous system (17). However, BMP2 has been shown to have a pathological role associated with the development of vascular inflammation and angiogenesis $(18,19)$. This was confirmed by discovering the BMP endothelial cell precursor derived regulator (BMPER), a negative regulator of BMPs signaling. BMPER was shown to protect against vascular inflammation and preserve normal retinal vascular homeostasis via suppression of BMP signaling pathway $(19,20)$. In addition to BMPER, BMP2 is regulated by various extracellular BMP-regulating factors such as noggin, chordin, and gremlin (21-25).
Similar to other TGF- $\beta$ family members, BMPs act through binding to a tetraheteromeric serine threonine kinase receptor complex (26). BMP receptors (BMPRs) compose of two BMPR type 1 receptors (BMPR1s) and two BMP type 2 receptors (BMPR2s). The biological effect of BMP2 is determined by its interaction with BMP type 1 receptor, since BMPR2 is a low affinity receptor $(27,28)$. There are four BMP type 1 receptor, Alk1/Acvrl1, Alk2/Acvr1, Alk3/Bmpr1a, and Alk6/Bmpr1b $(28,29)$. Affinity of various BMPs determines their different effects on endothelial cell function. For example, BMP9/10, which have an anti-angiogenic effect, have higher affinity to ALK1 whose deletion causes exuberant angiogenesis, suggesting that ALK1 regulates the angiostatic effect of BMP9/10 in endothelial cells $(30,31)$. On the other hand, ALK2, ALK3, and ALK6 that bind to BMP2, BMP4, and BMP6 are suggested to regulate their angiogenic signaling. Global deletion of these receptors is lethal and generally there is lack of understanding of their role in endothelial cell function in health and diseases such as diabetes and its microvascular complications as diabetic retinopathy (DR). Binding of BMPs to type I and II BMP receptors activates and phosphorylates receptor-regulated SMAD (R-SMAD) proteins (Smad 1, 5, and 9). Activated Smad 1, 5, and 9 proteins form a complex with co-Smad 4 and then translocate into the nucleus with subsequent interaction with other transcription factors to induce gene expression (32).

Our previous study was the first to demonstrate the upregulation of BMP2 in retinas of diabetic human subjects and in experimental mice as well as HRECs subjected to high glucose (HG). BMP2 also increased permeability, leukostasis, and inflammatory cytokines in HREC (33). However, the lack of understanding the molecular mechanism by which BMP2 induces REC dysfunction is a critical barrier in proposing it as a therapeutic target to treat DR. Thus, the aim of the current study is to delineate the molecular mechanisms by which BMP2 induces retinal endothelial cell barrier dysfunction which is essential for development of diabetic macular edema and pathological retinal neovascularization.

\section{MATERIALS AND METHODS}

\section{Experimental Animals}

We used streptozotocin (STZ)-injected C57BL/6J mice and Ins2Akita mice (C57BL/6-Ins2Akita/J Stock No: 003548/Akita, Jackson Laboratories) as experimental mouse models of type1 diabetes mellitus (DM), while homozygote $\mathrm{db} / \mathrm{db}(\mathrm{BKS} / \mathrm{db}-/-$, 
Jackson Laboratories) mice were used as mouse model for type 2 DM that develops spontaneous glucose intolerance and hyperglycemia at 4-8 weeks. Heterozygote mice $(\mathrm{db} /+)$, which usually show normal body weight, blood glucose, and plasma insulin, but have increased metabolic efficiency were also used for comparison (34). For STZ injected mice, 6-8 weeks old mice were injected with STZ $(55 \mathrm{mg} / \mathrm{kg}$, intra-peritoneal) for 3 consecutive days as previously described (35). Mice with plasma glucose level exceeding $250 \mathrm{mg} / \mathrm{dl}$ were considered diabetic. All experimental procedures were performed in accordance with the established guidelines of Association of Research in Vision and Ophthalmology statement for the Use of Animals in Ophthalmic and Vision Research, and were approved by the Institutional Animal Care and Use Committee (IACUC) of Augusta University. Blood was collected from cardiac puncture in heparinized coated tubes and the plasma was separated by centrifugation at $1,500 \mathrm{rpm}$ for $20 \mathrm{~min}$.

\section{Cell Culture}

HRECs were obtained from Cell Systems (Kirkland, WA) and grown to $80-90 \%$ confluence in Endothelial Basal Medium-2 (EBM-2, LONZA). Cells were then serum starved for $24 \mathrm{~h}$ before treatment and throughout the whole experiment (1-5 days). HRECs were treated with $\mathrm{rhBMP} 2(50 \mathrm{ng} / \mathrm{ml})$ with or without inhibitors of BMP signaling: Noggin $(200 \mathrm{ng} / \mathrm{ml})$ : an inhibitor of BMPs; LDN-193189 (LDN1, 200nM), a selective inhibitor of ALK2 and ALK3; LDN-212854 (LDN2, 200nM), an inhibitor of ALK2 with substantially weaker effects on ALK1 and ALK3. LDN1 and LDN2 were synthesized as previously described $(36,37)$. Moreover, HRECs were subjected to BMP2 treatment for 1-5 days in the presence or absence of various inhibitors such as inhibitors of VEGFR2 (SU5416, $10 \mu \mathrm{M}$ ) or p38 (SB202190), tyrosine kinase (genistein, $50 \mu \mathrm{M}$ ), or ERK (U0126, 10 $\mathrm{MM}$ ) followed by assessment of the changes in barrier function and VEGF expression. Transfection of HRECs was done as previously described $(35,38)$ to silence Smad1 using SignalSilence ${ }^{\circledR}$ Smad1 small interfering RNA (siRNA) (catalog \# 6223, Cell Signaling Technology). The high glucose conditioned media (DG-CM) were prepared by incubating HRECs with high glucose $(25 \mathrm{mM})$ for 5 days. Control conditioned media (LG-CM) were prepared by incubating cells with medium containing L-glucose (19.5 mM L-glucose, 5.5mM Dglucose; final concentration of $25 \mathrm{mM}$ ) for 5 days. Conditioned media were collected and concentrated 10 fold by spin-filtration (10 $\mathrm{kDa}$ cutoff, Millipore UFV4BK10) and added to the new HREC cultures.

\section{Electric Cell-Substrate Impedance Sensing Method}

Normalized transcellular electrical resistance (TER) was measured by electric cell-substrate impedance sensing [ECIS ${ }^{\circledR} \mathrm{Z} \theta$ (theta)] instrument (Applied Biophysics Inc, Troy, NY, USA) as previously described $(35,38,39)$. Briefly, HRECs were grown in 96-wells electrode arrays (catalog \# 96W20idf PET, Applied Biophysics Inc.) coated with $100 \mu \mathrm{M}$ cysteine and $0.02 \%$ gelatin. After confluence, cells were serum starved for $24 \mathrm{~h}$ and then treated with various treatments (BMP2 in the presence or absence of various inhibitors as above). For high glucose treatment, we used conditioned media (CM) that were collected from NG or HGtreated HRECs for 5 days. Fresh HRECs, then were subjected to these CM with or without various inhibitors (LDN1, LDN2, or noggin). TER was measured independently in each well over the time course of the experiment (4-5 days). Resistance values were normalized as the ratio of measured resistance to baseline resistance (normalized resistance) and plotted as a function of time.

\section{ELISA for BMP2 and VEGF}

Levels of BMP2 in mouse plasma and in the cultured media collected from HRECs subjected to VEGF (30 ng/ml) for $24 \mathrm{~h}$ were quantified using ELISA kits following the manufacturer's protocol (R\&D Systems, Minneapolis, MN). In brief, $100 \mu \mathrm{l}$ of Assay Diluent RD1-19 was first added to each well followed by addition of $50 \mu \mathrm{l}$ of the standards and samples. Plates were incubated at room temperature for $2 \mathrm{~h}$. Then, wells were washed three times using $400 \mu \mathrm{l}$ wash buffer for each well. Two hundred microliters of Monoclonal antibody specific for BMP-2 was then added per well and kept at room temperature for $2 \mathrm{~h}$. The wash step was repeated. Two hundred microliters of substrate solution was added to each well, protected from light and incubated at room temperature for $30 \mathrm{~min}$. To stop the reaction, stop solution was finally added $(50 \mu \mathrm{l})$ to each well. Detection of the optical density was done within $30 \mathrm{~min}$, using a microplate reader at wavelength $450 \mathrm{~nm}$ with correction at $540 \mathrm{~nm}$. Similar ELISA protocol was used to measure the levels of VEGF in the in the cultured media collected from HRECs that were subjected to BMP2 $(50 \mathrm{ng} / \mathrm{ml})$ for $24 \mathrm{~h}$ in the presence or absence of p38 or NFKB inhibitors SB202190 (10 $\mu \mathrm{M})$ and $\mathrm{JSH}-23(20 \mu \mathrm{M})$ respectively.

\section{Quantitative Real-Time RNA Polymerase Chain Reaction Arrays}

TaqMan arrays were used to measure messenger RNA (mRNA) levels of components of BMP2 signaling system in HRECs (Applied Biosystems, Foster City, CA). First, total RNA was extracted from HRECs subjected to rhBMP2, or HG using the RNeasy Mini Kit (Qiagen, Valencia, CA) according to manufacturer's instructions. A high capacity cDNA synthesis kit (Applied Biosystems, Foster City, CA) was then used to synthesize cDNA. Q-PCR was performed using TaqMan Fast Advanced Master Mix Kit (Applied Biosystems, Foster City, CA) and PCR amplification was performed using Step One Plus Realtime PCR System (Applied Biosystem, Foster City, CA). The thermocycling program consisted of $50^{\circ} \mathrm{C}$ for $2 \mathrm{~min}$ and $95^{\circ} \mathrm{C}$ for $2 \mathrm{~min}$, then $40 \mathrm{cycles}$ at $95^{\circ} \mathrm{C}$ for $3 \mathrm{~s}$, and $60^{\circ} \mathrm{C}$ for $3 \mathrm{~min}$. Three replicates were run for each gene in each sample with the readymade primer and probe sets in a 96-well plate. mRNA expression data was normalized to HPRT1 mRNA which has been used as the endogenous reference gene (housekeeping gene) as it does not exhibit significant expression changes between groups of samples. Calculations are based on the comparison of the distinct cycle determined by threshold values $(\mathrm{Ct})$ at a constant level of fluorescence and the relative quantification of mRNA expression was calculated with the $2^{\wedge}-\Delta \Delta \mathrm{Ct}$ method [Applied Biosystems 
User Bulletin $\mathrm{N}^{\circ} 2(\mathrm{P} / \mathrm{N}$ 4303859)]. The data were normalized with respect to HPRT1 mRNA and relative to a calibrator sample. LG-conditioned media-treated HRECs were used as calibrators. $\Delta \mathrm{Ct}=(\mathrm{Ct}$ target gene-Ct housekeeping gene). $\Delta \Delta \mathrm{Ct}=(\Delta \mathrm{Ct}$ sample $-\Delta \mathrm{Ct}$ normal non-diabetic $)$.

\section{Assessment of Effect of BMP2 Treatment on NF- $\kappa B$ and $p$-smad1/5/9 Nuclear Levels}

HRECs treated with BMP2 (50ng/ml) for $30 \mathrm{~min}$ were harvested and the nuclear extract was prepared using nuclear extraction kit (Abcam Inc., Cambridge, MA, USA, ab113474). Western blot analysis was performed to detect the NF- $\kappa \mathrm{B}$ (p65) and p-smad1/ $5 / 9$ levels in the prepared nuclear extract. Briefly, equal amount of protein was loaded on gradient gel (4 to $20 \%$, Pierce, Rockford, IL) and separated by sodium dodecyl sulfate polyacrylamide gel electrophoresis (SDS-PAGE). Thereafter, separated proteins were transferred into nitrocellulose membrane. The membrane was blocked using 5\% BSA (Bio-Rad, Hercules, CA), washed, and then incubated overnight at $4^{\circ} \mathrm{C}$ with primary antibody for NF$\kappa \mathrm{B}$ (Cell Signaling, Danvers, MA, USA, 1:300) and the loading control histone deacetylase (HDAC) (Abcam Inc., Cambridge, MA, USA). The primary antibody reaction was then detected by membrane incubation with peroxidase-conjugated secondary antibody. The protein bands were then visualized using enhanced chemiluminescence (ECL) western blot detection system (Thermo Scientific, SC. USA) and the intensity of the immunoreactivity was measured using optical density analysis software (Image Lab, Bio-Rad Laboratories, USA).

\section{Immunofluorescence of smad4 and NF-kB}

HRECs were stained with smad4 and NF- $\kappa B$ antibodies according to our previous procedure (40). Briefly, HRECs were fixed by using $2 \%$ paraformaldehyde followed by blockage in normal goat serum. Thereafter, HRECs were incubated with antibody against smad4 or NF- $\mathrm{KB}$ (Abcam, 1:100) overnight at $4^{\circ} \mathrm{C}$ followed by an incubation with Texas red labelled secondary antibody (1:500, Invitrogen, Eugene, OR). Finally, nuclei were stained with 4',6 diamidino-2-phenylindole (DAPI) mounting medium (Vector Laboratories, Burlingame, CA), and images were taken with confocal microscopy (LSM 510; Carl Zeiss, Thornwood, NY).

\section{Assessment of Reactive Oxygen Species}

DCF, the oxidation product of the reagent 2',7'-dichlorofluorescin diacetate (H2DCFDA; Molecular Probes), was used as a marker of cellular ROS including superoxide $\left(\mathrm{O}^{-}\right)$, hydrogen peroxide $(\mathrm{H} 2 \mathrm{O} 2)$ and peroxynitrite $\left(\mathrm{ONOO}^{-}\right)$according to a previous procedure (41). Briefly, cells in 96-well plates were incubated in $50 \mu \mathrm{l}$ of Earle's balanced salt solution containing $5 \mu \mathrm{M}$ H2DCFDA for $60 \mathrm{~min}$ and subjected to cellular DCF fluorescence measurement after BMP2 treatment (50 ng/ml for $24 \mathrm{~h}$ ). Fluorescence was measured using a spectrofluorometer (BioTek Instruments) with excitation at $488 \mathrm{~nm}$ and emission at $530 \mathrm{~nm}$. Similar procedures have been followed to measure the $\mathrm{O}_{2}^{-}$using the dihydroethidium (DHE, Sigma) which is more specific to superoxide generation than other ROS. The reaction intensity was measure at excitation $518 \mathrm{~nm}$ and emission $605 \mathrm{~nm}$.

\section{Assessment of Nitric Oxide Generation}

The assessment of nitric oxide (NO) was performed by measuring the total amount of nitrate and nitrite (which are the final products of NO) in HRECs after BMP2-treatment (50ng/ml for 18-24 h). The measurement was done by Fluorometric Assay Kit from Cayman Chemicals (Ann Arbor, MI, USA) in accordance with the manufacturer's instructions. Briefly, HRECs were cultured in a 24-well black plate and then treated with BMP2 (50ng/ml) for 18 $24 \mathrm{~h}$. Thereafter, the samples were mixed with assay buffer and nitrate reductase mixture was added and incubated for $30 \mathrm{~min}$ to convert all nitrate to nitrite. To measure the total nitrite, 2,3 diaminonaphthalene reagent provided as acid solution was added followed by $\mathrm{NaOH}$ to enhance the detection of the fluorescent product. The fluorescence intensity was measured using spectrofluorometer at the excitation and emission wavelengths of $365 \mathrm{~nm}, 430 \mathrm{~nm}$, respectively.

\section{Statistical Analysis}

Differences among groups as represented by the mean \pm SE were determined by the two-tailed $t$ test or one way analysis of variance (ANOVA) followed by a post hoc Tukey's test. Statistical significance among various groups was indicated by $\mathrm{P}$ value $<0.05$. For time-series studies, we used two ways ANOVA followed by a post hoc Tukey's test for multiple comparisons.

\section{RESULTS}

\section{Effect of Experimental Diabetes on Circulating Levels of BMP2}

Our previous study showed a marked increase in retinal expression of BMP2 in experimental diabetes as well as in diabetic human (33). Here, we tested the changes in the levels of BMP2 in blood samples of experimental type 1 and type 2 diabetic mice (Figure 1). Plasma levels of BMP2 showed significant increases in experimental mouse models of typel diabetes; the STZ $(1,568 \pm 309$ versus $626 \pm 130 \mathrm{pg} / \mathrm{ml}$ in control $)$ and Akita mice (1503 \pm 335 versus $638 \pm 171 \mathrm{pg} / \mathrm{ml}$ in control). The increase in circulating BMP2 in STZ and Akita mice was reported after 6 and 12 months from the onset of diabetes, respectively. We also measured plasma levels of BMP2 in the 6-week diabetic $\mathrm{db} / \mathrm{db}^{-1-}$ mouse model of type 2 diabetes in which there was significant increase ( $428 \pm 37$ versus $359 \pm 40 \mathrm{pg} / \mathrm{ml}$ in control). Although we noticed a significant difference between $\mathrm{db} / \mathrm{db}$ mice and its control, BMP2 levels in $\mathrm{db} / \mathrm{db}$ were obviously lower than in STZ and Akita mice and no significant difference was noticed between the homozygote $(\mathrm{db} / \mathrm{db})$ and its heterozygote group $(\mathrm{db} /+)$ in which the mean of plasma BMP2 level is $401 \pm 39 \mathrm{pg} / \mathrm{ml}$.

\section{rhBMP2 and High Glucose Upregulate BMP Receptors and Activate Canonical smad Pathway in Human Retinal Endothelial Cells}

Using RT-PCR we tested the effect of rhBMP2 on mRNA levels of BMPRs (ALK2, 3, 6, and BMPR2). Our data showed that BMP2 upregulates endothelial ALK3 and BMPRII (BMPR2) 
A

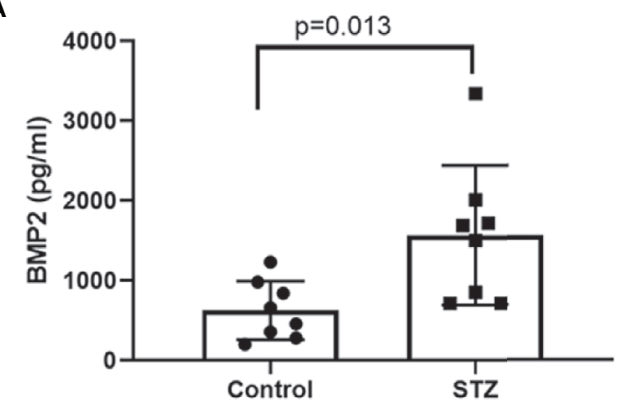

B
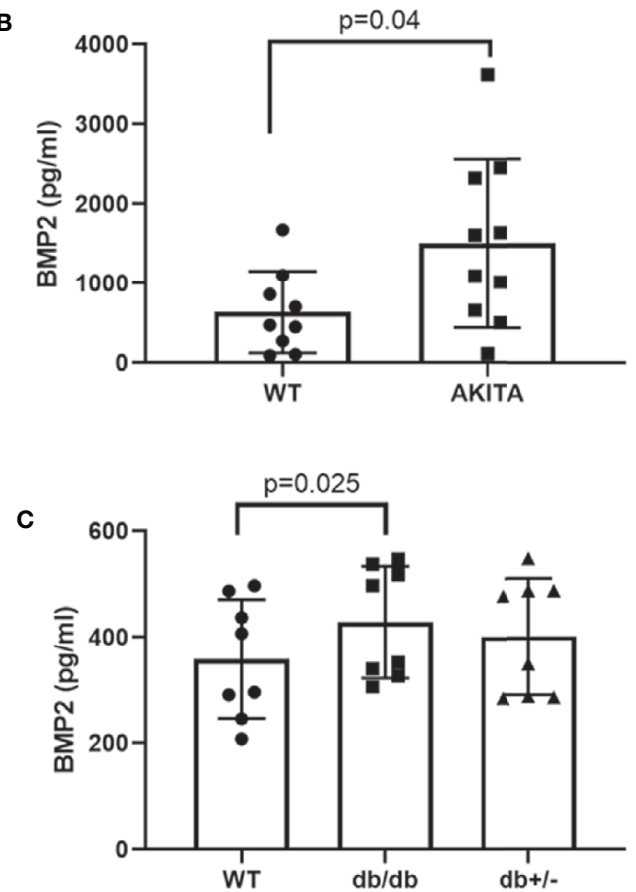

FIGURE 1 | Measurement of circulating levels of BMP2 by ELISA. Unpaired t-test was used to compare the plasma levels of BMP2 in streptozotocin (STZ) or Akita diabetic mice compared to control. Data analysis showing significant increases STZ-diabetic (A, p value $=0.013$ ), and 12-months diabetic Akita mice (B, $P=0.04)$. For multiple comparison, we used one way ANOVA followed by Tukey test to analyze the difference in plasma levels of BMP2 between $\mathrm{db} / \mathrm{db}$ (6 week diabetic), db/+, and control. There was significant modest increase in the levels of plasma BMP2 in $\mathrm{db} / \mathrm{db}$ compared to the control $(\mathbf{C}, p$ value $=0.025)$. There was no significant difference between $\mathrm{db} / \mathrm{db}$ and $\mathrm{db} /+. \mathrm{n}=8-10$.

significantly. There was also increases in the expression levels of ALK2 and ALK6, although these increases did not reach significant levels. rhBMP2 also upregulated the mRNA levels of BMP2 and TGF $\beta$ compared to the control (Figures 2A-F). The increased expression of BMP2 in HRECs subjected to exogenous rhBMP2 may establish a link between increased blood levels of BMP2 and its upregulation in retina during diabetes.

Activation of the smad effectors represents the canonical pathway of the BMP2 signaling and plays an essential role in mediating various biological functions of BMP2 by first phosphorylation and assembly of smad1/5/9/4 complex then translocation to the nucleus and initiating a transcription activity of target genes. Here, we evaluated the effect of rhBMP2 on the nuclear translocation of BMP-responsive smads system in HRECs. We first analyzed the amount of phosphor-smad1/5/9 in the nuclear extract of HRECs that were subjected to treatment with rhBMP2 or its vehicle for 30 min using western blot. While p-smad1/5/9 was absent in the nuclear extract of the control HRECs, we noticed a higher amount in the rhBMP2-treated HRECs. In addition to smad1/5/9, smad 4 is also a part of smad complex that translocates to nucleus upon activation by BMP2. Therefore, we tested its translocation to the nucleus by immunofluorescence (IF) that showed a marked increase of smad4 nuclear immunoreactivity in rhBMP2-treated HRECs compared to the control (Figures 2G, $\mathbf{H}$ ).

We also tested the effect of hyperglycemia on various components of BMP2 signaling pathway. RT-PCR analysis of mRNA expression of HRECs that were subjected to LG-CM or HG-CM treatment for 2 days showed significant increase in the expression of BMP2, BMP4, ALK3, smad9, smad4, and TGF $\beta$ mRNA by HG-CM compared to the osmotic control LG-CM (Figure 2I). We also noticed marked increases in ALK2, smad1, and SMAD5 mRNA although this increase did not reach statistical significance. Interestingly, HG-CM treatment induced a significant decrease in the expression of BMP binding endothelial regulator (BMPER) mRNA, a known negative regulator of BMP2 functions (42).

\section{BMP2 Induces P38/NFkB Non-Canonical Pathway in Human Retinal Endothelial Cells}

Activation of p38 MAPK contributes to the biological functions of the BMP2/ALKs system and its role in DR has been well-established (43-47). We hypothesize that in addition to smad canonical pathway, p38 MAPK/NFKB signaling pathway also contributes to the permeability and inflammatory effects of BMP2 in the retina. In support to this hypothesis, analysis of the levels of phosphorylated p38 MAPK in HRECs showed $1.5 \pm 0.2$ fold increase by rhBMP2 compared to the vehicle treated cells (Figure 3A). The interaction between p38 MAPK and the transcription factor $\mathrm{NF \kappa B}$ is implicated in the regulation of several inflammatory cytokines and oxidative stress mediators (48-51). Here, in addition to p38 MAPK activation, rhBMP2 also induced nuclear translocation of NFKB in HRECs as shown by western blot $(3.3 \pm 0.5)$ fold increase vs. control) and increased NFאB nuclear immunoreactivity by IF (Figures 3B, C respectively).

\section{Presence of a Positive Feedback Between BMP2 and VEGF Expression in Human Retinal Endothelial Cells}

VEGF is a key player in the development of retinal endothelial cell dysfunction in DR and has been shown to be regulated by both smad canonical $(52,53)$ and non-canonical $(54,55)$ pathways. We tested whether there is an interaction between BMP2 and VEGF in retinal endothelial cells. While BMP2 induced significant increases in VEGF levels in HRECs $(1,284 \pm$ 

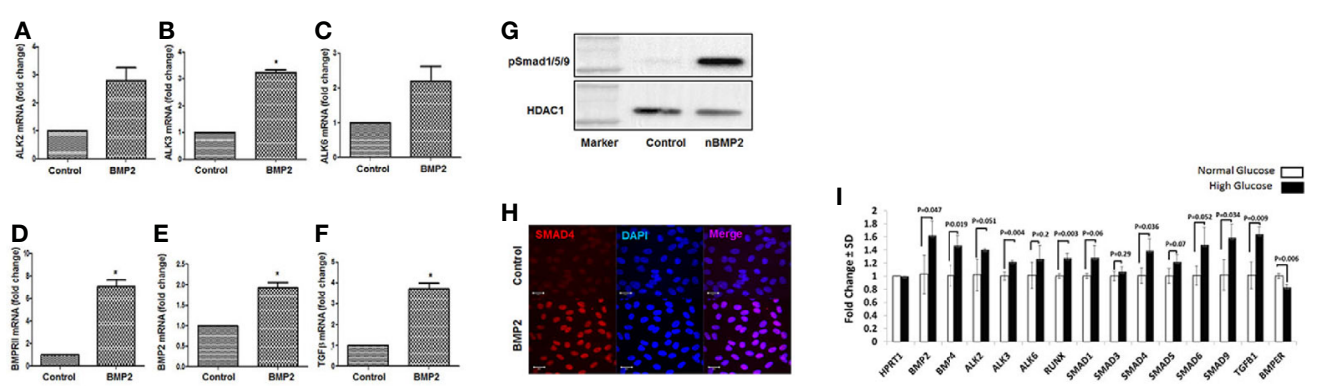

FIGURE 2 | Effect of rhBMP2 or high glucose on BMP receptors and smad system. RT-PCR analysis of the messenger RNA (mRNA) of BMP receptors Alk2 (A), ALK3 (B), ALK6 (C) and BMPRII (D), BMP2 (E) and TGF $\beta$ (F) in human retinal endothelial cells (HRECs) subjected to rhBMP2 (50ng/ml) for 24 h. There is a significant increase in the expression of BMP receptors ALK3 and BMPRII. There was also a marked increase ALK2 and ALK6 expression although this increase did not reach to significant levels. Also, BMP2 treatment induced significant increase in BMP2 and TGF $\beta$ mRNA expression. Western blotting of HRECs nuclear extract showing upregulation of nuclear psmad1/5/9 (G). IF of smad4 showing marked increase in nuclear (blue) immunereactivity of smad 4 (red) by rhBMP2 (H). $\mathrm{n}=6$ ( ${ }^{\star} \mathrm{P}<$ 0.05). (I) The effect of hyperglycemia on various components of BMP2 signaling pathway. RT-PCR analysis of mRNA expression of various components of BMP2 signaling pathway in HRECs that were subjected to LG-CM or HG-CM treatment for 2 days.

$209.9 \mathrm{pg} / \mathrm{ml}$; mean $\pm \mathrm{SD})$ versus the control $(686 \pm 102.5 \mathrm{pg} / \mathrm{ml}$; mean \pm SD) (Figure 4A), inhibition of p38 or NFKB by SB202190 or JSH-2 respectively prevented this increase and reduced the levels of VEGF in HRECs to $0.6 \pm 0.1$ and $0.4 \pm$ 0.03 fold, respectively, versus the control (Figures $4 \mathrm{~B}, \mathrm{C}$ ).

Interestingly, treatment of HRECs with VEGF (30ng/ml) also upregulated BMP2 expression ( $2.5 \pm 1.0$ fold increase $v s$. control) (Figure 4D) suggesting presence of a positive feedback between BMP2 and VEGF in the retina, which could contribute to the development of vascular abnormalities in DR.

\section{Inhibition of smad Pathway Attenuates rhBMP2-Induced Human Retinal Endothelial Cells Barrier Dysfunction}

Transcellular electrical resistance (TER) reflects the integrity of cellular barrier function. To evaluate the extent to which BMPRs contribute to the permeability effect of BMP2, we tested the effect of specific inhibitors that target BMPRs or their binding to BMP2 on rhBMP2-induced changes in TER of HRECs using the ECIS. For example, we used noggin that blocks the binding of BMP2 to its receptors and LDN1 and LDN2 that block ALK2 and ALK3 receptors. Consistent with our previous study (33), rhBMP2 disrupted the barrier function of HRECs as shown by a significant decrease in the TER of HRECs. This disruptive effect was significantly attenuated by noggin, LDN1, and LDN2 (Figure 5A) supporting the role of BMPRs in mediating the permeability effect of BMP2 in HRECs. Silencing of smad1 (Figure 5B) also preserved HRECs barrier function under BMP2 treatment as compared to HRECs transfected with mock siRNA. These findings suggest a role for the smad pathway in BMP2-mediated HREC dysfunction.

\section{Inhibition of p38, or VEGF Signaling Attenuates BMP2-Induced Human Retinal Endothelial Cells Barrier Dysfunction}

In addition to the effect of BMPRs inhibition, we also tested whether inhibition of non-canonical pathway represented by 338 and VEGF may impact the disruptive effect of rhBMP2 on
HRECs TER using ECIS. Here, our experiments showed that effect of BMP2 on endothelial TER was significantly abrogated by inhibitors of VEGFR2 (SU5416, $10 \mu \mathrm{M}$ ) or p38 (SB202190) (Figures 5C, D respectively) On the other hand, inhibition of tyrosine kinase by genistein $(50 \mu \mathrm{M})$ compared to VEGFR2 inhibition or ERK by U0126 $(10 \mu \mathrm{M})$ compared to p38 MAPK inhibition did not prevent rhBMP2-induced reduction of TER.

\section{Inhibition of BMP2 Signaling Preserves Human Retinal Endothelial Cell Barrier Function Under Hyperglycemia}

We also tested whether inhibition of BMP signaling offers protection against hyperglycemia-induced barrier dysfunction in HRECs. Barrier dysfunction usually occurs in HRECs after several days of $\mathrm{HG}$ treatment ( $>5$ days) that affect the viability of HRECs cells and also the $\mathrm{pH}$ of the media. Therefore, we used CM of HRECs subjected to NG or HG for 5 days to treat new HRECs in the presence or absence of various BMP2 signaling inhibitors (LDN1, LDN2, or noggin). Our data showed that noggin LDN1and LDN2 preserve HRECs barrier function under HG condition (Figure 5E).

\section{BMP2 Induces Generation of Reactive Oxygen Species in Human Retinal Endothelial Cells}

Oxidative stress is a key player in mediating endothelial cell dysfunction in various diseases including diabetic retinopathy (38). Therefore, we tested the impact of rhBMP2 on HRECs redox status. Treatment of HRECs with rhBMP2 induced significant increase in the superoxide $\left(\mathrm{O} 2^{-}\right)$generation as measured by DHE color reaction. DHE that only labels $\mathrm{O}_{2}{ }^{-}$ reached the peak after $10 \mathrm{~min}$ followed by time-dependent decrease although it stayed higher than control group (Figure 6A). We also assessed ROS generation using the H2-DCF a fluorogenic dye that measures the levels of various cellular ROS including $\mathrm{O}_{2}^{-}, \mathrm{H} 2 \mathrm{O} 2$, and $\mathrm{ONOO}^{-}$. Analysis of H2-DCF in HRECs showed a significant increase in ROS generation by rhBMP2. 

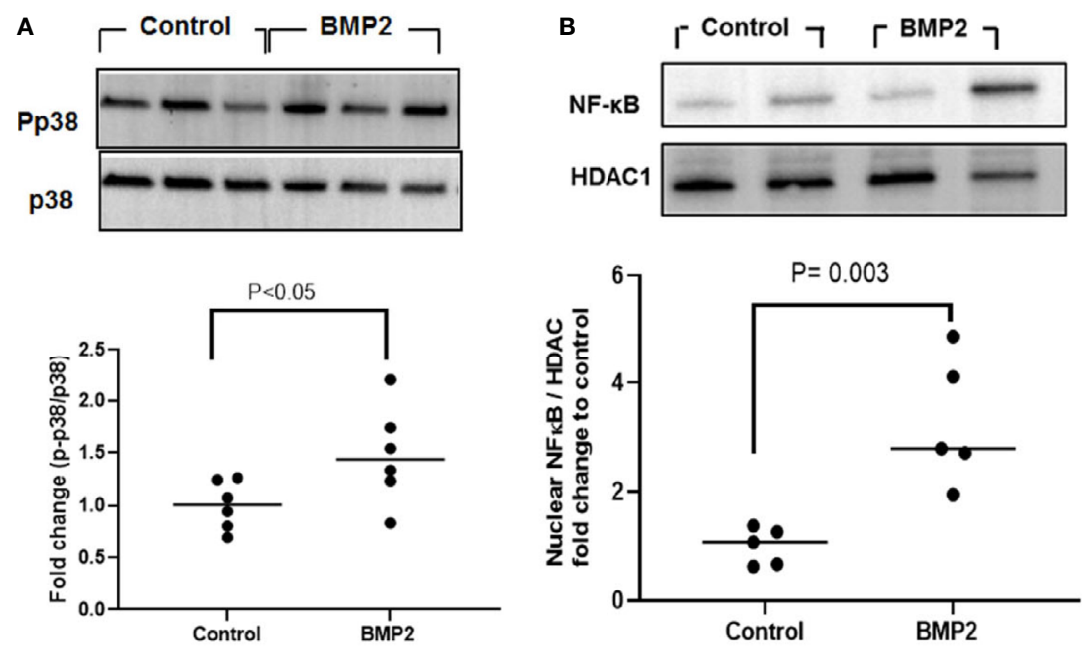

C
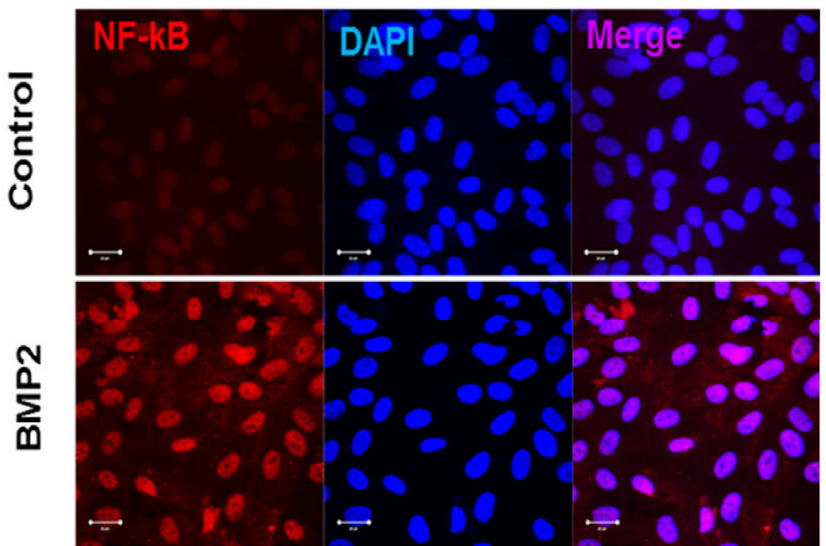

FIGURE 3 | Western blot analysis of the effect of rhBMP2 on p38 and NFkB. Unpaired t-test was used to compare the effect of rhBMP2 on p-p38 and nuclear $\mathrm{NF \kappa B}$ compared to control. Densitometry analysis showing significant increase in the levels of p-p38 and the nuclear NFKB in human retinal endothelial cells (HRECs) compared to the control (A, B respectively). IF (C) also showing marked increase in the nuclear (blue) immunoreactivity of NFKB (red) in HRECs subjected to rhBMP2 compared to the control. $n=5-6$.

However, contrary to DHE $\left(\mathrm{O}^{-}\right), \mathrm{H} 2$-DCF started to increase after $5 \mathrm{~h}$ from adding the rhBMP2 and continued to increase for several $\mathrm{h}$ compared to the control (Figure 6B). This suggests that while $\mathrm{O}_{2}^{-}$ decreases over the time, total ROS that includes also $\mathrm{H} 2 \mathrm{O} 2$ and $\mathrm{ONOO}^{-}$in addition to $\mathrm{O}_{2}^{-}$continue to increase. This increase of ROS generation by rhBMP2 was significantly attenuated by ALK inhibitor LDN1.

We tested whether the consistent decrease of $\mathrm{O}_{2}^{-}$is attributed to generation of nitric oxide (NO) that reacts rapidly with $\mathrm{O}_{2}^{-}$to form $\mathrm{ONOO}^{-}$and in turn increases $\mathrm{H} 2$-DCF reaction over time. For this purpose we tested the effect of rhBMP2 on the levels of eNOS and its activity (nitric oxide generation) as a known source of ROS particularly the $\mathrm{ONOO}^{-}$by its reaction with $\mathrm{O}^{-}$. RTPCR of HRECs showed significant increase of eNOS mRNA by rhBMP2 compared to the control (Figure 6C) and this was associated with a significant increase in NO generation (Figure
6D). Interestingly, the increase in NO showed a similar pattern to $\mathrm{O}^{-}$generation in which it decreases over time although it consistently stays higher than the control (Figure 6F).

\section{DISCUSSION}

Our previous study (33) demonstrated upregulation of BMP2 in retina of diabetic human subjects and experimental diabetic mice and upregulation of inflammatory cytokines and leukostasis in cultured retinal endothelial cells subjected to BMP2 treatment. It was the first study to underscore BMP2 as a possible player in the development of microvascular dysfunction in DR. The current study extends to investigate in some details the mechanism by which BMP2 regulates retinal endothelial cell barrier function. The main findings of the current study are: 1) significant increase 

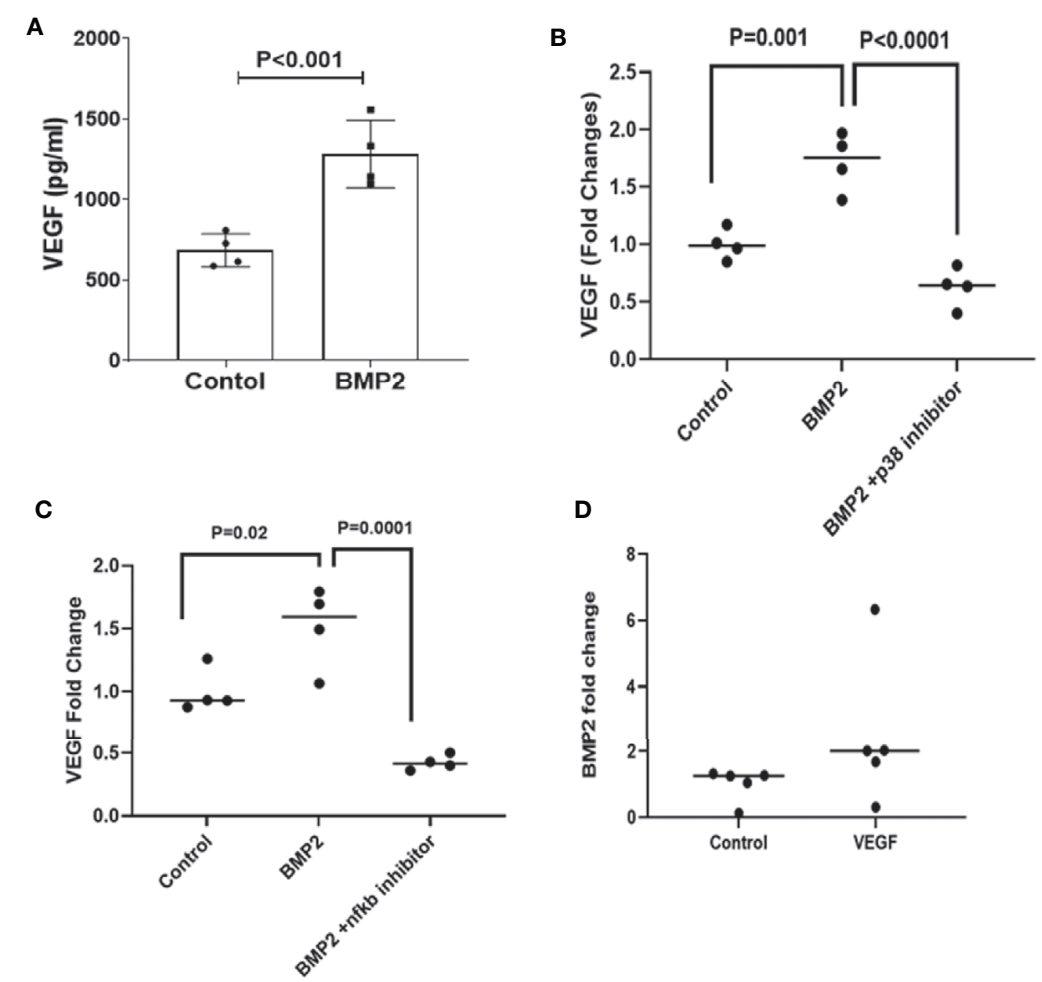

FIGURE 4 | ELISA of VEGF and BMP levels lin human retinal endothelial cells (HRECs). One-way ANOVA followed by a post hoc Tukey's test was used to compare the effect of BMP2 on VEGF levels in the presence or absence of p38 or NFkb inhibitors in cultured HRECs. Data analysis are showing significant increases in the

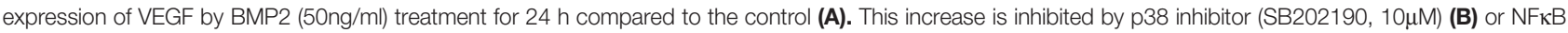
inhibitor (JSH23, $20 \mu \mathrm{M})$ (C). Furthermore, ELISA of BMP2 levels in the condition medium of VEGF-treated HRECs is showing a significant increase by VEGF (30ng/ml for $24 \mathrm{~h}$ ) compared to the control (D). Analysis of the difference between control and VEGF treatment was done using unpaired t-test.

in the circulating BMP2 in experimental models of type 1 and type 2 diabetes, 2) induction of both canonical and noncanonical pathways in HRECs by BMP2, 3) attenuation of BMP2-induced permeability by inhibitors of canonical or noncanonical pathways, 4) induction of oxidative stress in HRECs subjected to BMP2.

The role of BMP signaling system in endothelial cell dysfunction has attracted several investigators who showed permeability and angiogenic potential of the activated BMP signaling $(33,51,56,57)$. However, the relationship between diabetes in general and its complications in particular and activated BMP signaling has not yet been established. Here, we provide the first evidence for the increase in the levels of circulating BMP2 in mouse model of type 1 (Akita and streptozotocin) and type 2 diabetes ( $\mathrm{db} / \mathrm{db}$ mice) compared to their controls. Although there was significant increase in circulating BMP2 in $\mathrm{db} / \mathrm{db}$ mice compared to their control wild type, this increase was modest compared to STZ and Akita models and was not significant compared to the heterozygote $\mathrm{db} /+$ group. This raises a question regarding this difference between type 1 and type 2 diabetes and whether relative long exposure to hyperglycemia in STZ (6 months) and Akita (12 months) versus 1012 weeks in $\mathrm{db} / \mathrm{db}$ played a role in this differential effect of diabetes on plasma levels of BMP2. In addition, to the observed in vivo increase in BMP2 by hyperglycemia, treatment of HRECs with HG upregulated mRNA of BMP2 and BMP4 and their downstream effectors such as ALKs, SMADs, and TGF $\beta$ mimicking the effect of rhBMP2 treatment. Contrary, this increase of BMP2 signaling components by $\mathrm{HG}$ was associated with significant reduction in BMPER, a known negative regulator of BMP2 signaling (42). These data suggest that the balance between BMP2 signaling system and its negative regulators such as BMPER is important to maintain normal endothelial cell function.

Since our previous study showed upregulation of the retinal BMP2 (33) and the current one showing upregulation of the circulating BMP2 in diabetes, we suggest presence of a positive feedback between the circulating BMP2 and the retinal BMP2. Moreover, increases in the circulating BMP2 was reported here at early and late stage of diabetes, 6 week-12 months from onset of the experimental diabetes leading us to hypothesize that the circulating level of BMP2 could be a biomarker in the diabetic patients. This may correlate the circulating levels of BMP2 with development of diabetic complications such as DR. Further investigations are needed to prove this hypothesis in the diabetic patients.

BMP2 mediates its biological functions through activation of two independent or linked pathways, the smad (canonical) and p38 MAPK (noncanonical) pathways. Activation of both 
A

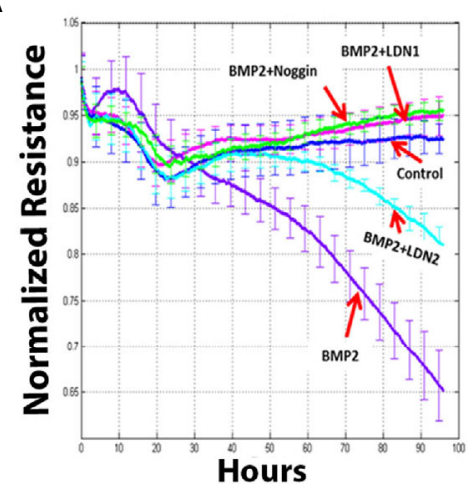

C

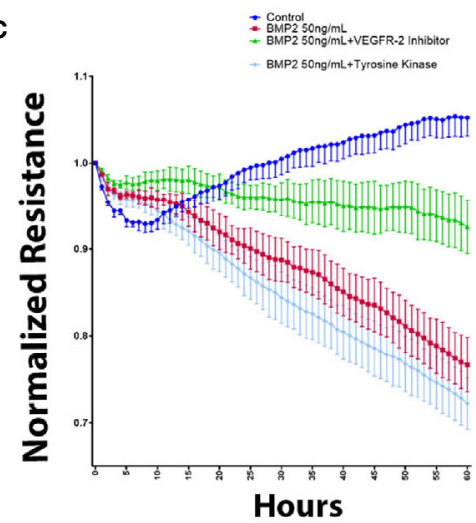

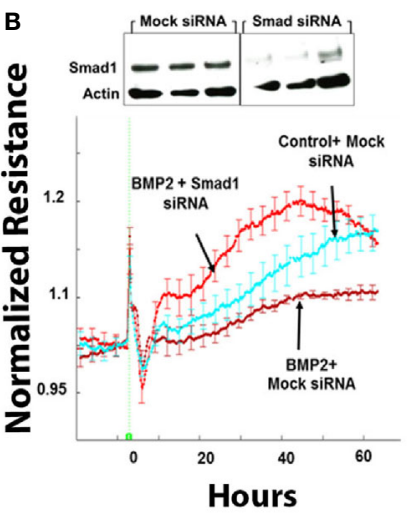

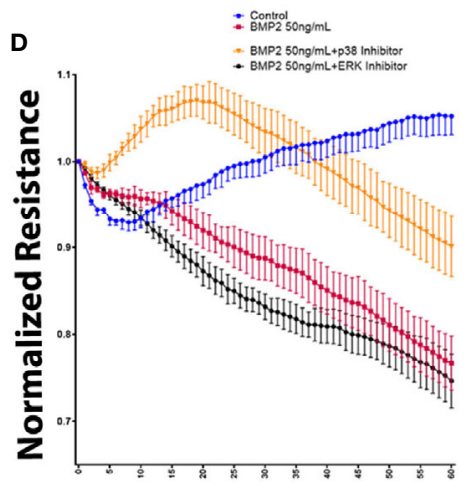

Hours

$\mathbf{E}$

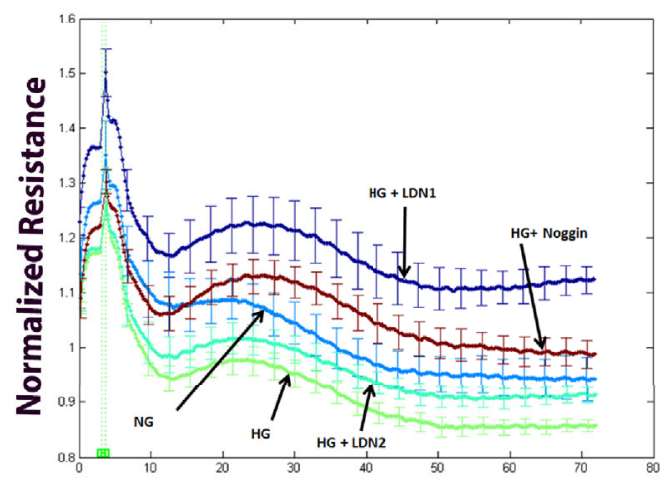

Hours

FIGURE 5 | Effect of BMP2 on trans-endothelial electrical resistance (ECIS). ECIS analysis showing significant decreases in the trans-endothelial cell electrical resistance (TER) of human retinal endothelial cells (HRECs) treated with rhBMP2 ( $50 \mathrm{ng} / \mathrm{ml}$ for $4-5$ days). Effect of rhBMP2 was significantly attenuated by the inhibitors of BMP receptors, LDN1 and LDN2 as well as by the noggin that prevents BMP2 from binding its receptors (A). Effect of rhBMP2 on the TER of HRECs was also attenuated by silencing smad1 using smad1 small interfering RNA (siRNA) compared to the mock siRNA (B). Inhibition of VEGFR2 by SU5416, $10 \mu$ M (C), or p38 by SB202190, $10 \mu \mathrm{M}$ (D) showing significant attenuation of the rhBMP2-induced reduction of the TER in HRECs. However, inhibition of tyrosine kinase by G-6055 9Genistein 10 $\mu \mathrm{M}$ (C) or MERK by U0126 10MM (D) did not prevent the effect of BMP2-induced changes in the TER of HRECs. Similarly, incubation of HRECs in CM of HG-treated HRECs induced significant decrease in TER over time and this effect was attenuated by noggin, LDN1, and LDN2. (E) Data points represent the mean of 4-6 wells at the same time point+SE. Two way ANOVA followed by a post hoc Tukey's test. It was used to compare different treatments over time.

pathways is downstream from BMP2 binding to its receptors. The biological effect of BMP2 is determined by its interaction with BMPR1 particularly (ALK2, 3, and 6), since BMPR2 is a low affinity receptor $(27,28)$. Treatment of HRECs with rhBMP2 upregulated expression of BMPR mRNAs particularly ALK3 and BMPRII that showed significant increases. There was also marked increase in ALK2 and ALK6 although this increase did not reach significant levels. In agreement with previous reports $(29,58)$, endothelial ALK2, 3, and 6 as well as BMPRII are implicated in BMP2 signaling in retinal endothelial cells. Moreover, the disruptive effect of rhBMP2 on HRECs barrier function as demonstrated by a significant decrease of the TER 


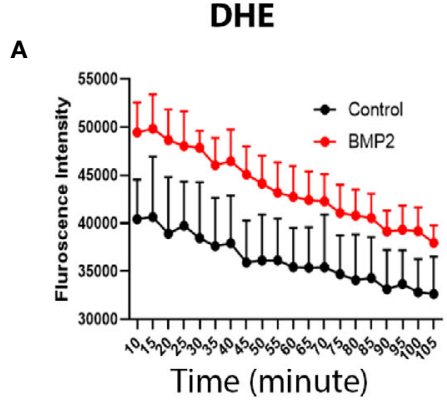

C

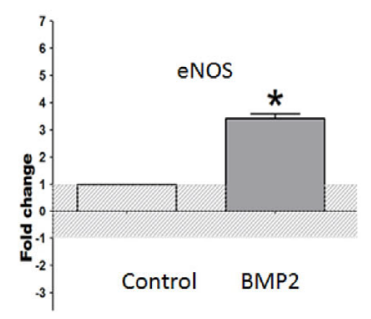

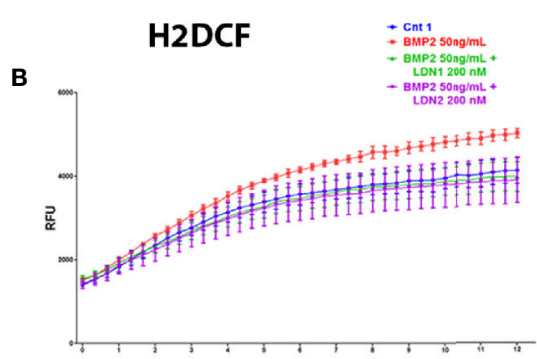

Time (hour)

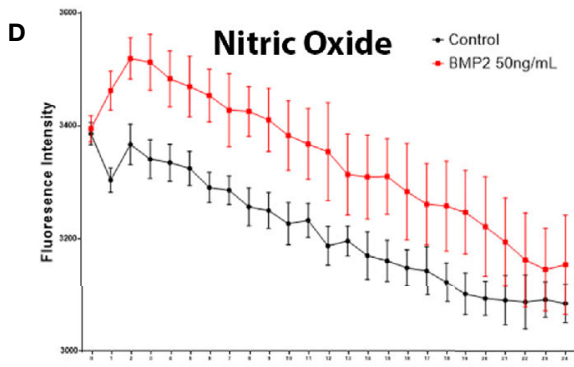

Time (hour)

FIGURE 6 | Measurement of intracellular reactive oxygen species by dihydroethidium or DHE (A) and H2-Dichlorofluorescine or DCF (B) showing significant increases in the superoxide and other ROS, respectively by BMP2. The increase in ROS was prevented by the pharmacological inhibitor of BMPR (LDN1). RT-PCR (C) showing significant increases in the levels of eNOS messenger RNA (mRNA) in the human retinal endothelial cells (HRECs) by BMP2. * $<$ 0.05. Finally, measurement of the eNOS activity by measuring nitric oxide (NO) generation using the fluorescence reaction (D) showing significant increases by the BMP2. Differences among groups as represented by the mean \pm SD were determined by the two-tailed $t$ test or two way ANOVA followed by a post hoc Tukey's test.

was prevented by the BMPR inhibitors, noggin, LDN1, and LDN2. ALK2 and 3 have been shown to play important role in the proangiogenic effect of BMP2 and thus suggested to be selective target for the antiangiogenic therapy (51). A recent report has emphasized both ALK2, ALK3, and BMPRII in BMP2-induced retinal vascular development and targeted deletion of any of them in endothelial cells led to significant impairment of normal vascular development in retina (59).

We next investigated the impact of rhBMP2 on the nuclear translocation of smad complex which is required to induce the transcription activity of BMP2-dependent genes. Our experiments using western blot analysis of the HRECs nuclear extracts or immunofluorescence showed nuclear translocation of smad1/5/9 and smad4 respectively by rhBMP2 treatment. We then, asked if smad activation contributes to the permeability effect of BMP2. For this purpose, we tested the effect of smad1 silencing on rhBMP2-induced barrier dysfunction in HRECs. Smad1 siRNA preserved the TER of HRECs in the presence of rhBMP2 compared to the MOCK siRNA suggesting involvement of the smad system in the BMP2-induced retinal endothelial cell dysfunction.

In addition to the smad system, activation of the non-canonical pathway as represented by $\mathrm{p} 38 \mathrm{MAPK} / \mathrm{NF} \mathrm{B}$ and dependent genes have also been shown to contribute to the biological effects of BMP2 (48-51). Therefore, we evaluated the hypothesis that this noncanonical pathway also contributes to the disruptive effect of rhBMP2 on the HRECs barrier function. To test this hypothesis, we examined the direct effect of rhBMP2 on the phosphorylation/ activation levels of $\mathrm{p} 38$, nuclear translocation of $\mathrm{NF \kappa B}$ as well as VEGF expression as one of the essential molecules that could be regulated by activated $\mathrm{p} 38 / \mathrm{NF \kappa B}$ signaling. Our experiments demonstrated a significant increase in the levels of phosphorylated-p38 MAPK and the nuclear translocation of $\mathrm{NF} \kappa \mathrm{B}$. In addition, inhibition of $\mathrm{p} 38$ or NFKB significantly attenuated the rhBMP2-induced upregulation of VEGF, a key player in endothelial dysfunction in diabetic retinopathy. We next investigated if the activated non-canonical pathway contributes to rhBMP2-induced HRECs barrier dysfunction using specific inhibitors of 338 MAPK. Inhibition of p38 MAPK preserved the TER in the rhBMP2-treated HRECs compared to the ERK inhibitor. Our findings also suggest that $\mathrm{p} 38 / \mathrm{NFKB}$ is implicated in BMP2induced endothelial dysfunction probably via a VEGF-dependent mechanism. In agreement to our data, BMP receptor activation has been reported to selectively induce activation of the p38 mitogenactivated protein kinase (MAPK) in contrast to the ERK1/2 MAP kinases to promote tumor angiogenesis (60).

The potential role of VEGF signaling in BMP2-induced HRECs barrier dysfunction was demonstrated by the significant improvement of the HRECs TER by the VEGFR2 inhibition. VEGF has been shown to induce BMP2 expression in the microvascular endothelial cells (61). Our experiments using HRECs also showed an upregulation of BMP2 expression by VEGF treatment, suggesting presence of a positive feedback between VEGF and BMP2 in the retinal endothelial cells. We 
previously established a positive cross talk between BMP2 and VEGF to enhance the osteogenesis and angiogenesis in the critical size bone defect model $(62,63)$. VEGF and BMP2 have shown to have a synergistic effect in inducing osteogenesis, angiogenesis, and metastasis, therefore, administration or inhibition of both VEGF and BMP2 was suggested as a possible strategy to enhance bone healing or decreasing the incidence of cancer metastases respectively $(56,57)$. We previously showed that BMP2 also upregulate VEGF production in the retinal Müller cells. Current and previous data may establish an interesting relation between VEGF and BMP2 especially in diabetes in which increased circulating BMP2, retinal BMP2 and VEGF elicit positive feedback in both endothelial and Müller cells to contribute to the retinal microvascular dysfunction in diabetes. VEGF has been established as a downstream target from smad system and p38/ $\operatorname{NF\kappa B}(54,55)$, thus we conclude that activation of the canonical and non-canonical pathways in HRECs by rhBMP2 converges at VEGF signaling to induce HRECs barrier dysfunction. In addition to studying the direct effect of rhBMP2 on HRECs barrier integrity in the presence or absence of its signaling inhibitors, we also evaluated the effect BMP2 signaling inhibitors on HG-induced barrier dysfunction. Our data showed preservation of HRECs barrier under hyperglycemic insult by BMP2 signaling inhibitors suggesting inhibition of BMP2 signaling as potential therapeutic intervention to protect blood-retinal barrier in diabetes.

We and others have reported the critical role of ROS such as $\mathrm{O}_{2}^{-}, \mathrm{ONOO}^{-}$and $\mathrm{H} 2 \mathrm{O} 2$ in inducing endothelial permeability and angiogenesis in DR (64-66). We tested if the BMP2 elicits any effect on redox status of the retinal endothelial cells. Our data, showed significant increases of ROS generation in HRECs over an extended period of time by the rhBMP treatment. This effect was attenuated by pharmacological inhibition of BMPR using the LDN1 and LDN2. The peak of increased superoxide as measured by DHE staining was noticed after $10 \mathrm{~min}$ from adding rhBMP2 followed by a consistent decrease over time. Contrary the total amount of ROS generation $\left(\mathrm{O}_{2}^{-}, \mathrm{ONOO}^{-}\right.$, and $\mathrm{H} 2 \mathrm{O} 2$ ) as measured by $\mathrm{H} 2 \mathrm{DCF}$ continued to increase by the rhBMP2 treatment over time. This led us to test the effect of BMP2 on eNOS, a known source of ROS and NO. There was a significant increase in the mRNA of eNOS by rhBMP2. This was associated with a significant increase in NO generation that showed a similar pattern to superoxide generation in which NO continued to decrease over time. This led us to suggest that the generated $\mathrm{O}_{2}^{-}$, and $\mathrm{NO}$ combine to generate $\mathrm{ONOO}^{-}$and this was reflected on the consistent increase of the $\mathrm{H} 2 \mathrm{DCF}$ reaction opposite to the consistent decrease in both superoxide and NO. Of note, increased oxidative stress leads to NOS uncoupling and NO-quenching by excess superoxide to form $\mathrm{ONOO}^{-}$(67). This may explain the inverse relationship noticed between the total ROS and both $\mathrm{O}_{2}^{-}$and $\mathrm{NO}$ over an extended period.

In conclusion, the current study underscores the circulating BMP2 in addition to the retinal BMP2 as a potential player and probably a biomarker in diabetes complications such as DR. The study also characterizes the signaling mechanisms by which BMP2 may contribute to the retinal endothelial cell dysfunction especially hyperpermeability in DR. The underlying mechanism involves BMPRs and subsequent activation of canonical and non-canonical pathways. Downstream from these signaling pathways, VEGF and oxidative stress are probably contributing factors to BMP2induced retinal endothelial cell dysfunction. Hence, the use of BMP signaling system inhibitors alone or in conjunction with anti-VEGF could be a novel approach to prevent the microvascular dysfunction in DR.

\section{DATA AVAILABILITY STATEMENT}

The original contributions presented in the study are included in the article/Supplementary Material. Further inquiries can be directed to the corresponding author.

\section{ETHICS STATEMENT}

The animal study was reviewed and approved by the Institutional Animal Care and Use Committee (IACUC) of Augusta University.

\section{AUTHOR CONTRIBUTIONS}

All authors listed have made a substantial, direct, and intellectual contribution to the work and approved it for publication.

\section{FUNDING}

This research was funded by the National Eye Institute grants R01EY030054-01A1 and R01EY023315 (MA-S); the American Heart Association Grant 18CDA34080403 (AI), NIH core grant P30EY004068 to the Department of Ophthalmology, Visual and Anatomical Sciences (OVAS), and a Research to Prevent Blindness unrestricted grant to the Department of OVAS, Wayne State University, Detroit, MI, USA; Chinese Cultural Bureau to (FW) and (MW); and Egyptian Cultural bureau (KH, NE, and KE). 1R01EY029751-01 to AT.

\section{SUPPLEMENTARY MATERIAL}

The Supplementary Material for this article can be found online at: https://www.frontiersin.org/articles/10.3389/fimmu.2020.568795/ full\#supplementary-material

SUPPLEMENTARY DATA SHEET 1 | Original Western blot for the p-p38 and NFkB data in HRECs subjected to BMP2 and BMP4. 


\section{REFERENCES}

1. Berger EA, Carion TW, Jiang Y, Liu L, Chahine A, Walker RJ, et al. betaAdrenergic receptor agonist, compound 49b, inhibits TLR4 signaling pathway in diabetic retina. Immunol Cell Biol (2016) 94(7):656-61. doi: 10.1038/ icb.2016.21

2. Lanzetta P, Sarao V, Scanlon PH, Barratt J, Porta M, Bandello F, et al. Fundamental principles of an effective diabetic retinopathy screening program. Acta Diabetol (2020). doi: 10.1007/s00592-020-01541-5

3. Semeraro F, Morescalchi F, Cancarini A, Russo A, Rezzola S, Costagliola C. Diabetic retinopathy, a vascular and inflammatory disease: Therapeutic implications. Diabetes Metab (2019) 45(6):517-27. doi: 10.1016/j.diabet. 2019.04.002

4. Bhandari S, Nguyen V, Fraser-Bell S, Mehta H, Viola F, Baudin F, et al. Ranibizumab or Aflibercept for Diabetic Macular Edema: Comparison of 1Year Outcomes from the Fight Retinal Blindness! Registry. Ophthalmology (2019). doi: 10.1016/j.ophtha.2019.10.006

5. Chung YR, Kim YH, Ha SJ, Byeon HE, Cho CH, Kim JH, et al. Role of Inflammation in Classification of Diabetic Macular Edema by Optical Coherence Tomography. J Diabetes Res (2019) 2019:8164250. doi: 10.1155/ 2019/8164250

6. Monickaraj F, McGuire P, Das A. Cathepsin D plays a role in endothelialpericyte interactions during alteration of the blood-retinal barrier in diabetic retinopathy. FASEB J (2018) 32(5):2539-48. doi: 10.1096/fj.201700781RR

7. Park DY, Lee J, Kim J, Kim K, Hong S, Han S, et al. Plastic roles of pericytes in the blood-retinal barrier. Nat Commun (2017) 8:15296. doi: 10.1038/ ncomms 15296

8. Simo-Servat O, Simo R, Hernandez C. Circulating Biomarkers of Diabetic Retinopathy: An Overview Based on Physiopathology. J Diabetes Res (2016) 2016:5263798. doi: 10.1155/2016/5263798

9. Rossino MG, Casini G. Nutraceuticals for the Treatment of Diabetic Retinopathy. Nutrients (2019) 11(4):771. doi: 10.3390/nu11040771

10. Afarid M, Meshksar A, Salehi A, Safarpour MM. EVALUATION OF THE EFFECT OF TOPICAL INTERFERON alpha2b AS A COMPLEMENTARY TREATMENT OF MACULAR EDEMA OF PATIENTS WITH DIABETIC RETINOPATHY: A Double-Blind Placebo-Controlled Randomized Clinical Trial Study. Retina (2019). doi: 10.1097/IAE.0000000000002465

11. Nasrabadi D, Rezaeiani S, Eslaminejad MB, Shabani A. Improved Protocol for Chondrogenic Differentiation of Bone Marrow Derived Mesenchymal Stem Cells -Effect of PTHrP and FGF-2 on TGFbeta1/BMP2-Induced Chondrocytes Hypertrophy. Stem Cell Rev Rep (2018) 14(5):755-66. doi: 10.1007/s12015-018-9816-y

12. Wang C, Silverman RM, Shen J, O'Keefe RJ. Distinct metabolic programs induced by TGF-betal and BMP2 in human articular chondrocytes with osteoarthritis. J Orthop Translat (2018) 12:66-73. doi: 10.1016/j.jot.2017. 12.004

13. Bieniasz M, Oszajca K, Eusebio M, Kordiak J, Bartkowiak J, Szemraj J. The positive correlation between gene expression of the two angiogenic factors: VEGF and BMP-2 in lung cancer patients. Lung Cancer (2009) 66(3):319-26. doi: 10.1016/j.lungcan.2009.02.020

14. Kwon SJ, Lee GT, Lee JH, Iwakura Y, Kim WJ, Kim IY. Mechanism of protumorigenic effect of BMP-6: neovascularization involving tumor-associated macrophages and IL-1a. Prostate (2014) 74(2):121-33. doi: 10.1002/ pros. 22734

15. Zhang L, Ye Y, Long X, Xiao P, Ren X, Yu J. BMP signaling and its paradoxical effects in tumorigenesis and dissemination. Oncotarget (2016) 7(47):7820618. doi: $10.18632 /$ oncotarget.12151

16. Morrell NW, Bloch DB, ten Dijke P, Goumans MJ, Hata A, Smith J, et al. Targeting BMP signalling in cardiovascular disease and anaemia. Nat Rev Cardiol (2016) 13(2):106-20. doi: 10.1038/nrcardio.2015.156

17. Liu C, Tian G, Tu Y, Fu J, Lan C, Wu N. Expression pattern and clinical prognostic relevance of bone morphogenetic protein-2 in human gliomas. Jpn J Clin Oncol (2009) 39(10):625-31. doi: 10.1093/jjco/hyp094

18. Simoes Sato AY, Bub GL, Campos AH. BMP-2 and -4 produced by vascular smooth muscle cells from atherosclerotic lesions induce monocyte chemotaxis through direct BMPRII activation. Atherosclerosis (2014) 235(1):45-55. doi: 10.1016/j.atherosclerosis.2014.03.030
19. Helbing T, Rothweiler R, Ketterer E, Goetz L, Heinke J, Grundmann S, et al. BMP activity controlled by BMPER regulates the proinflammatory phenotype of endothelium. Blood (2011) 118(18):5040-9. doi: 10.1182/blood-2011-03339762

20. Moreno-Miralles I, Ren R, Moser M, Hartnett ME, Patterson C. Bone morphogenetic protein endothelial cell precursor-derived regulator regulates retinal angiogenesis in vivo in a mouse model of oxygen-induced retinopathy. Arterioscler Thromb Vasc Biol (2011) 31(10):2216-22. doi: 10.1161/ATVBAHA.111.230235

21. Brazil DP, Church RH, Surae S, Godson C, Martin F. BMP signalling: agony and antagony in the family. Trends Cell Biol (2015) 25(5):249-64. doi: 10.1016/j.tcb.2014.12.004

22. Heinke J, Juschkat M, Charlet A, Mnich L, Helbing T, Bode C, et al. Antagonism and synergy between extracellular BMP modulators Tsg and BMPER balance blood vessel formation. J Cell Sci (2013) 126(Pt 14):3082-94. doi: $10.1242 /$ jcs. 122333

23. Kisonaite M, Wang X, Hyvonen M. Structure of Gremlin-1 and analysis of its interaction with BMP-2. Biochem J (2016) 473(11):1593-604. doi: 10.1042/ BCJ20160254

24. Rosen V. BMP and BMP inhibitors in bone. Ann N Y Acad Sci (2006) 1068:19-25. doi: 10.1196/annals.1346.005

25. Tsialogiannis E, Polyzois I, Oak Tang Q, Pavlou G, Tsiridis E, Heliotis M, et al. Targeting bone morphogenetic protein antagonists: in vitro and in vivo evidence of their role in bone metabolism. Expert Opin Ther Targets (2009) 13(1):123-37. doi: 10.1517/14728220802637725

26. Wu M, Chen G, Li YP. TGF-beta and BMP signaling in osteoblast, skeletal development, and bone formation, homeostasis and disease. Bone Res (2016) 4:16009. doi: 10.1038/boneres.2016.9

27. Pouliot F, Blais A, Labrie C. Overexpression of a dominant negative type II bone morphogenetic protein receptor inhibits the growth of human breast cancer cells. Cancer Res (2003) 63(2):277-81.

28. Townson SA, Martinez-Hackert E, Greppi C, Lowden P, Sako D, Liu J, et al. Specificity and structure of a high affinity activin receptor-like kinase 1 (ALK1) signaling complex. J Biol Chem (2012) 287(33):27313-25. doi: 10.1074/jbc.M112.377960

29. Mazerbourg S, Sangkuhl K, Luo CW, Sudo S, Klein C, Hsueh AJ. Identification of receptors and signaling pathways for orphan bone morphogenetic protein/ growth differentiation factor ligands based on genomic analyses. J Biol Chem (2005) 280(37):32122-32. doi: 10.1074/jbc.M504629200

30. Zhu Q, Kim YH, Wang D, Oh SP, Luo K. SnoN facilitates ALK1-Smad1/5 signaling during embryonic angiogenesis. J Cell Biol (2013) 202(6):937-50. doi: $10.1083 /$ jcb.201208113

31. Larrivee B, Prahst C, Gordon E, del Toro R, Mathivet T, Duarte A, et al. ALK1 signaling inhibits angiogenesis by cooperating with the Notch pathway. Dev Cell (2012) 22(3):489-500. doi: 10.1016/j.devcel.2012.02.005

32. Chen D, Zhao M, Mundy GR. Bone morphogenetic proteins. Growth Factors (2004) 22(4):233-41. doi: 10.1080/08977190412331279890

33. Hussein KA, Choksi K, Akeel S, Ahmad S, Megyerdi S, El-Sherbiny M, et al. Bone morphogenetic protein 2: a potential new player in the pathogenesis of diabetic retinopathy. Exp Eye Res (2014) 125:79-88. doi: 10.1016/j.exer. 2014.05.012

34. Burke SJ, Batdorf HM, Burk DH, Noland RC, Eder AE, Boulos MS, et al. db/db Mice Exhibit Features of Human Type 2 Diabetes That Are Not Present in Weight-Matched C57BL/6J Mice Fed a Western Diet. J Diabetes Res (2017) 2017:8503754. doi: 10.1155/2017/8503754

35. Ibrahim AS, Saleh H, El-Shafey M, Hussein KA, El-Masry K, Baban B, et al. Targeting of 12/15-Lipoxygenase in retinal endothelial cells, but not in monocytes/macrophages, attenuates high glucose-induced retinal leukostasis. Biochim Biophys Acta Mol Cell Biol Lipids (2017) 1862(6):63645. doi: 10.1016/j.bbalip.2017.03.010

36. Cuny GD, Yu PB, Laha JK, Xing X, Liu JF, Lai CS, et al. Structure-activity relationship study of bone morphogenetic protein (BMP) signaling inhibitors. Bioorg Med Chem Lett (2008) 18(15):4388-92. doi: 10.1016/ j.bmcl.2008.06.052

37. Mohedas AH, Xing X, Armstrong KA, Bullock AN, Cuny GD, Yu PB. Development of an ALK2-biased BMP type I receptor kinase inhibitor. ACS Chem Biol (2013) 8(6):1291-302. doi: 10.1021/cb300655w 
38. Ibrahim AS, Elshafey S, Sellak H, Hussein KA, El-Sherbiny M, Abdelsaid M, et al. A lipidomic screen of hyperglycemia-treated HRECs links 12/15Lipoxygenase to microvascular dysfunction during diabetic retinopathy via NADPH oxidase. J Lipid Res (2015) 56(3):599-611. doi: 10.1194/jlr.M056069

39. Ibrahim AS, Mander S, Hussein KA, Elsherbiny NM, Smith SB, Al-Shabrawey M, et al. Hyperhomocysteinemia disrupts retinal pigment epithelial structure and function with features of age-related macular degeneration. Oncotarget (2016) 7(8):8532-45. doi: 10.18632/oncotarget.7384

40. Ibrahim AS, Tawfik AM, Hussein KA, Elshafey S, Markand S, Rizk N, et al. Pigment epithelium-derived factor inhibits retinal microvascular dysfunction induced by 12/15-lipoxygenase-derived eicosanoids. Biochim Biophys Acta (2015) 1851(3):290-8. doi: 10.1016/j.bbalip.2014.12.017

41. Ibrahim AS, El-Remessy AB, Matragoon S, Zhang W, Patel Y, Khan S, et al. Retinal microglial activation and inflammation induced by amadori-glycated albumin in a rat model of diabetes. Diabetes (2011) 60(4):1122-33. doi: $10.2337 / \mathrm{db} 10-1160$

42. Moser M, Binder O, Wu Y, Aitsebaomo J, Ren R, Bode C, et al. BMPER, a novel endothelial cell precursor-derived protein, antagonizes bone morphogenetic protein signaling and endothelial cell differentiation. Mol Cell Biol (2003) 23(16):5664-79. doi: 10.1128/MCB.23.16.5664-5679.2003

43. Choi H, Jeong BC, Kook MS, Koh JT. Betulinic acid synergically enhances BMP2-induced bone formation via stimulating Smad 1/5/8 and p38 pathways. J BioMed Sci (2016) 23(1):45. doi: 10.1186/s12929-016-0260-5

44. Du Y, Tang J, Li G, Berti-Mattera L, Lee CA, Bartkowski D, et al. Effects of p38 MAPK inhibition on early stages of diabetic retinopathy and sensory nerve function. Invest Ophthalmol Vis Sci (2010) 51(4):2158-64. doi: 10.1167/iovs. 09-3674

45. Liu X, Ye F, Xiong H, Hu DN, Limb GA, Xie T, et al. IL-1beta induces IL-6 production in retinal Muller cells predominantly through the activation of p38 MAPK/NF-kappaB signaling pathway. Exp Cell Res (2015) 331(1):223-31. doi: 10.1016/j.yexcr.2014.08.040

46. Adachi T, Teramachi M, Yasuda H, Kamiya T, Hara H. Contribution of p38 MAPK, NF-kappaB and glucocorticoid signaling pathways to ER stressinduced increase in retinal endothelial permeability. Arch Biochem Biophys (2012) 520(1):30-5. doi: 10.1016/j.abb.2012.01.014

47. Dong N, Chang L, Wang B, Chu L. Retinal neuronal MCP-1 induced by AGEs stimulates TNF-alpha expression in rat microglia via p38, ERK, and NFkappaB pathways. Mol Vis (2014) 20:616-28.

48. Mao CY, Wang YG, Zhang X, Zheng XY, Tang TT, Lu EY. Double-edgedsword effect of IL-1beta on the osteogenesis of periodontal ligament stem cells via crosstalk between the NF-kappaB, MAPK and BMP/Smad signaling pathways. Cell Death Dis (2016) 7:e2296. doi: 10.1038/cddis.2016.204

49. Wang L, Li JY, Zhang XZ, Liu L, Wan ZM, Li RX, et al. Involvement of p38MAPK/NF-kappaB signaling pathways in osteoblasts differentiation in response to mechanical stretch. Ann BioMed Eng (2012) 40(9):1884-94. doi: 10.1007/s10439-012-0548-x

50. Feng PC, Ke XF, Kuang HL, Pan LL, Ye Q, Wu JB. BMP2 secretion from hepatocellular carcinoma cell HepG2 enhances angiogenesis and tumor growth in endothelial cells via activation of the MAPK/p38 signaling pathway. Stem Cell Res Ther (2019) 10(1):237. doi: 10.1186/s13287-019-1301-2

51. Benn A, Hiepen C, Osterland M, Schutte C, Zwijsen A, Knaus P. Role of bone morphogenetic proteins in sprouting angiogenesis: differential BMP receptordependent signaling pathways balance stalk vs. tip cell competence. FASEB J (2017) 31(11):4720-33. doi: 10.1096/fj.201700193RR

52. He C, Chen X. Transcription regulation of the vegf gene by the BMP/Smad pathway in the angioblast of zebrafish embryos. Biochem Biophys Res Commun (2005) 329(1):324-30. doi: 10.1016/j.bbrc.2005.01.133

53. Ai WJ, Li J, Lin SM, Li W, Liu CZ, Lv WM. R-Smad signaling-mediated VEGF expression coordinately regulates endothelial cell differentiation of rat mesenchymal stem cells. Stem Cells Dev (2015) 24(11):1320-31. doi: 10.1089/ scd.2014.0253

54. Hu J, Li T, Du S, Chen Y, Wang S, Xiong F, et al. The MAPK signaling pathway mediates the GPR91-dependent release of VEGF from RGC-5 cells. Int J Mol Med (2015) 36(1):130-8. doi: 10.3892/ijmm.2015.2195

55. Huang C, Zhu HJ, Li H, Li QX, Li FM, Cheng L, et al. p38-MAPK pathway is activated in retinopathy of microvascular disease of STZ-induced diabetic rat model. Eur Rev Med Pharmacol Sci (2018) 22(18):5789-96. doi: 10.1002/ jor.22277

56. Mattar T, Friedrich PF, Bishop AT. Effect of rhBMP-2 and VEGF in a vascularized bone allotransplant experimental model based on surgical neoangiogenesis. J Orthop Res (2013) 31(4):561-6. doi: 10.1002/jor.22277

57. Weiss KR, Cooper GM, Jadlowiec JA, McGough RL 3rd, Huard J. VEGF and BMP expression in mouse osteosarcoma cells. Clin Orthop Relat Res (2006) 450:111-7. doi: 10.1097/01.blo.0000229333.98781.56

58. Manning G, Whyte DB, Martinez R, Hunter T, Sudarsanam S. The protein kinase complement of the human genome. Science (2002) 298(5600):1912-34. doi: $10.1126 /$ science. 1075762

59. Lee HW, Chong DC, Ola R, Dunworth WP, Meadows S, Ka J, et al. Alk2/ ACVR1 and Alk3/BMPR1A Provide Essential Function for Bone Morphogenetic Protein-Induced Retinal Angiogenesis. Arterioscler Thromb Vasc Biol (2017) 37(4):657-63. doi: 10.1161/ATVBAHA.116.308422

60. Raida M, Clement JH, Leek RD, Ameri K, Bicknell R, Niederwieser D, et al. Bone morphogenetic protein 2 (BMP-2) and induction of tumor angiogenesis. J Cancer Res Clin Oncol (2005) 131(11):741-50. doi: 10.1007/s00432-0050024-1

61. Bouletreau PJ, Warren SM, Spector JA, Peled ZM, Gerrets RP, Greenwald JA, et al. Hypoxia and VEGF up-regulate BMP-2 mRNA and protein expression in microvascular endothelial cells: implications for fracture healing. Plast Reconstr Surg (2002) 109(7):2384-97. doi: 10.1097/00006534-20020600000033

62. Akeel S, El-Awady A, Hussein K, El-Refaey M, Elsalanty M, Sharawy M, et al. Recombinant bone morphogenetic protein-2 induces up-regulation of vascular endothelial growth factor and interleukin 6 in human preosteoblasts: role of reactive oxygen species. Arch Oral Biol (2012) 57 (5):445-52. doi: 10.1016/j.archoralbio.2011.10.002

63. Hussein KA, Zakhary IE, Elawady AR, Emam HA, Sharawy M, Baban B, et al. Difference in soft tissue response between immediate and delayed delivery suggests a new mechanism for recombinant human bone morphogenetic protein 2 action in large segmental bone defects. Tissue Eng Part A (2012) 18 (5-6):665-75. doi: 10.1089/ten.tea.2011.0148

64. Pacher P, Obrosova IG, Mabley JG, Szabo C. Role of nitrosative stress and peroxynitrite in the pathogenesis of diabetic complications. Emerging new therapeutical strategies. Curr Med Chem (2005) 12(3):267-75. doi: 10.2174/ 0929867053363207

65. Zheng L, Kern TS. Role of nitric oxide, superoxide, peroxynitrite and PARP in diabetic retinopathy. Front Biosci (Landmark Ed) (2009) 14:3974-87. doi: $10.2741 / 3505$

66. Al-Shabrawey M, Bartoli M, El-Remessy AB, Ma G, Matragoon S, Lemtalsi T, et al. Role of NADPH oxidase and Stat3 in statin-mediated protection against diabetic retinopathy. Invest Ophthalmol Vis Sci (2008) 49(7):3231-8. doi: 10.1167/iovs.08-1754

67. Santilli F, Cipollone F, Mezzetti A, Chiarelli F. The role of nitric oxide in the development of diabetic angiopathy. Horm Metab Res (2004) 36(5):319-35. doi: $10.1055 / \mathrm{s}-2004-814489$

Conflict of Interest: PY is a co-founder and scientific advisory board member for Keros Therapeutics, Inc., and holds stock and intellectual property (IP) as a result of his work done in the lab that has been licensed by the company. PY is also a consultant to Acceleron Pharma Inc. and holds IP related to technology stemming from work done in the lab that was licensed by that company.

The remaining authors declare that the research was conducted in the absence of any commercial or financial relationships that could be construed as a potential conflict of interest.

Copyright (c) 2021 Al-Shabrawey, Hussein, Wang, Wan, Elmasry, Elsherbiny, Saleh, Yu, Tawfik and Ibrahim. This is an open-access article distributed under the terms of the Creative Commons Attribution License (CC BY). The use, distribution or reproduction in other forums is permitted, provided the original author(s) and the copyright owner(s) are credited and that the original publication in this journal is cited, in accordance with accepted academic practice. No use, distribution or reproduction is permitted which does not comply with these terms. 